\title{
A Survey of Gratitude Awareness of Chinese College Students
}

\author{
Xiaojuan Li, Yuping Li \\ Jinan University, Guangzhou, China \\ Email: 41273375@qq.com
}

How to cite this paper: $\mathrm{Li}, \mathrm{X}$. J., \& Li, Y. P. (2017). A Survey of Gratitude Awareness of Chinese College Students. Psychology, 8, 2446-2452.

https://doi.org/10.4236/psych.2017.814154

Received: November 10, 2017

Accepted: December 15, 2017

Published: December 18, 2017

Copyright $\odot 2017$ by authors and Scientific Research Publishing Inc. This work is licensed under the Creative Commons Attribution International License (CC BY 4.0).

\begin{abstract}
By doing a questionnaire survey of the gratitude awareness situation among the students of one university in Guangzhou, we had an overview of the gratitude awareness of the students. Based on this survey, it is advocated that college students' gratitude education should be promoted on the basis of Chinese traditional cultural education; disadvantaged students should be paid more attention; teachers should set good examples; and the gratitude education should be enriched to make it more social; etc.
\end{abstract}

\section{Keywords}

College Students, Gratitude Awareness Situation, Survey

\section{Introduction}

Gratitude, as a traditional virtue and an essential requirement, should be a built- in moral trait of college students who are the elite group of a society. However, in recent years, the gratitude awareness and actions among college students attracted social attention, and aroused researcher's reflection. Nowadays, most post-90s college students are the only child in their families, and they "are active, pursue individuality, and adopt a variety of values" (Niu, 2011). This paper, through a questionnaire survey of the students in a university, has probed into this problem: what kind of value would be selected by the post-90s college students.

\section{Factors and Respondents}

\subsection{Factors}

In this questionnaire, the demographic characteristics of the post-90s students have been investigated, including gender, origins, home place, grade, major, family economic situation and family members, etc., which can be analyzed, so 
that something about the relation between those factors and their influence on gratitude awareness can be unfolded. And an approach can be worked out to be helpful to the gratitude education of college students.

\subsection{Respondents}

The respondents of this questionnaire are the college students in a southern comprehensive university: 230 questionnaires were given, and 224 of them were returned, the response rate is $96 \%$. To make this data analysis more scientific, statistics package for social science (SPSS 11.0) was used in this paper. Analysis types were univariate descriptive statistics and bivariate interactive classification statistics, with Chi-Square Test as an assist.

The description of the demographic, the relation between the demographic characteristics of the respondents is from Table 1.

\section{An Analysis of the Questionnaire and the Conclusion}

Through the analysis of this questionnaire, the relation between the demographic factors and the gratitude awareness can be revealed from the four aspects:

Table 1. The demographic characteristics of the respondents $(\mathrm{N}=224)$.

\begin{tabular}{|c|c|c|c|c|}
\hline Items & Categories & Number & Percent (\%) & Accumulated percent (\%) \\
\hline \multirow{2}{*}{ Gender } & male & 70 & 31.3 & 31.3 \\
\hline & female & 154 & 68.8 & 100 \\
\hline \multirow{2}{*}{ Origin } & mainland & 145 & 64.7 & 31.3 \\
\hline & non-mainland & 79 & 35.3 & 100 \\
\hline \multirow{3}{*}{ Grade } & freshman & 102 & 45.5 & 45.5 \\
\hline & sophomore & 70 & 31.3 & 76.8 \\
\hline & juniors and seniors & 52 & 23.2 & 100 \\
\hline \multirow[t]{2}{*}{ Major } & $\begin{array}{l}\text { science engineering } \\
\text { agriculture medical } \\
\text { science }\end{array}$ & 61 & 27.2 & 27.2 \\
\hline & $\begin{array}{c}\text { literature history } \\
\text { economy management }\end{array}$ & 163 & 72.8 & 100 \\
\hline \multirow{3}{*}{$\begin{array}{l}\text { Family } \\
\text { member }\end{array}$} & the only child & 71 & 31.7 & 31.7 \\
\hline & with 2 siblings & 80 & 35.7 & 67.4 \\
\hline & with 2 or more siblings & 73 & 32.6 & 100 \\
\hline \multirow{2}{*}{ Homeplace } & city & 60 & 26.8 & 26.8 \\
\hline & countryside & 164 & 73.2 & 100 \\
\hline \multirow{3}{*}{$\begin{array}{l}\text { Family } \\
\text { economic } \\
\text { situation }\end{array}$} & bad & 34 & 15.2 & 15.2 \\
\hline & average & 149 & 66.5 & 81.7 \\
\hline & good & 41 & 18.3 & 100 \\
\hline
\end{tabular}




\subsection{The Factor of Homeplace}

Students with different demographic factors reach a consensus about the importance of thanksgiving in their growth. As for the lack of gratitude awareness, students from the countryside are more serious, while the students from city take this problem easy. Among the answers of the question "Is gratitude an essential quality of college students?", "Yes" takes up over 90\%, which is the only all-agreed viewpoint among college students. The post-90s, having been educated on Confucianism under the modern social background, have all been deeply influenced with Chinese culture. They all regard gratitude as an essential quality of a man, which lays the solid foundation for the promotion of gratitude education, makes it enforceable.

The answers of the question "Do you think the classmates around you are lacking of the sense of gratitude?" vary. There are $53.3 \%$ of the students from city and $35.4 \%$ of students from countryside choosing the answer "not yet", and the other two options "lacking seriously", and "is lacking" are $46.6 \%$ and $64.6 \%$ respectively. According to the data, there is a relation between homeplace and the lack of gratitude awareness, which is what the survey told us. The results of $\mathrm{X}^{2}\left(\mathrm{X}^{2}=6.523, \mathrm{p}=0.044<0.05\right)$ have also indicated the significance of this relation. All the data above come from Table 2. Due to China's long time unbalanced economic development, the urban-rural gap is widening. Students from city are more satisfied and happier toward their life than the students from countryside; thus they are more grateful.

\subsection{The Factor of Homeplace and Family Members}

The person that is regarded to be thanked the most is mainly parents among the students. But there are still some different opinions, due to the factors of homeplace and family members.

"Parents" are "the people I want to thank the most" of students from city, while there is a little difference of the students from countryside. Analysis indicates that, homeplace is relevant with their object of thanksgiving. The result of $\mathrm{X}^{2}\left(\mathrm{X}^{2}=5.049, \mathrm{p}=0.025<0.05\right)$ also tells the significance of this relation. The data are showed in Table 3.

"Parents" are still "the person I want to thank the most" among students, whether they are from a family of three or more. At present, college students are

Table 2. The relation between homeplace and gratitude awareness.

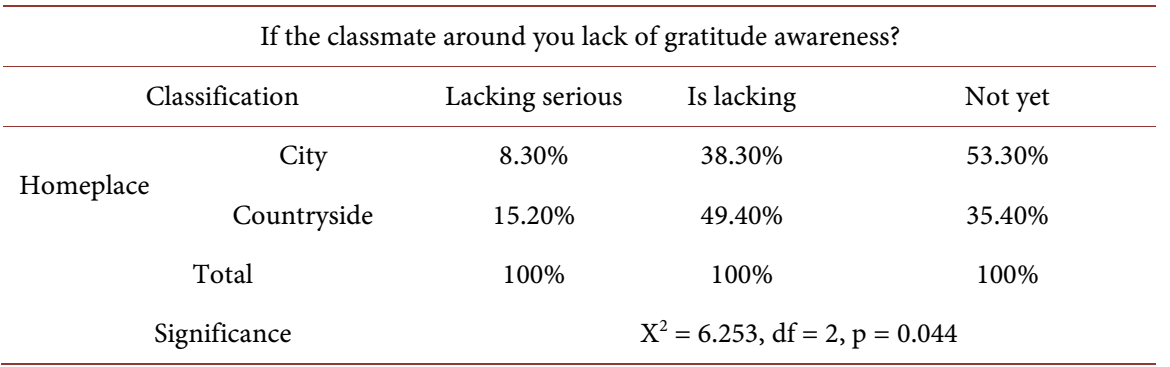


Table 3. The relation between homeplace and the object of thanksgiving.

\begin{tabular}{|c|c|c|c|}
\hline \multicolumn{4}{|c|}{ The person that to whom you feel the most grateful } \\
\hline \multicolumn{2}{|c|}{ Classification } & \multirow{2}{*}{$\begin{array}{c}\text { Parents } \\
100 \%\end{array}$} & $\begin{array}{c}\text { Others } \\
\text { (individual, society or country) }\end{array}$ \\
\hline \multirow{2}{*}{ Homeplace } & City & & \\
\hline & Countryside & $92.10 \%$ & $7.90 \%$ \\
\hline \multicolumn{2}{|c|}{ Total } & $100 \%$ & $100 \%$ \\
\hline \multicolumn{2}{|c|}{ Significance } & \multicolumn{2}{|c|}{$\mathrm{X}^{2}=5.049, \mathrm{df}=1, \mathrm{p}=0.025$} \\
\hline
\end{tabular}

mainly "post-90s" and mostly the only child of their family. In a family of three, parents are the only companion in the child's growth process, so parents are the most important persons in the child's heart. $92.7 \%$ of the only child chose parents as their object to thank, $88.8 \%$ of the students with one sibling chose "parents" as their object to thank, and $97.3 \%$ of the students with 2 or more siblings chose parents also.

Analysis indicates that family members are an important factor in this survey. The result of $\mathrm{X}^{2}\left(\mathrm{X}^{2}=6.753, \mathrm{p}=0.037<0.05\right)$ shows the importance of this relation. Students with one sibling feel less lonely, and are more independent. Students with 2 or more siblings are more grateful to their parents, because this kind of family, due to the number of children and huge family expenses, costs more. The data showed above are from Table 4.

\subsection{The Factor of Gender and Homeplace}

Students of different sex and homeplace showed a different attitude toward their alma mater. Girls are more emotional and grateful than boys; and students from countryside hold various attitudes.

To the question "Will you come back to visit your alma mater after your graduation?", $55.7 \%$ of boys and $72.1 \%$ of girls, $81.7 \%$ of students from city and $61.6 \%$ of the students from countryside chose the answer "Yes, I am concerned."; $38.6 \%$ of boys and $27.9 \%$ of girls, $18.3 \%$ of students from city and $36 \%$ of the students from countryside chose the answer "I will visit it if it is by chance."; $5.7 \%$ of boys and $0 \%$ of girls, $0 \%$ of students from city and $2.4 \%$ of the students from countryside are inclined to the answer "No, nothing interests me".

The data tells that there is a relation between gender, homeplace and students' feeling of gratitude to their alma mater. The result of the Chi-Square test is $\mathrm{X}^{2}=$ $12.471(\mathrm{p}=0.002<0.05)$ and $\mathrm{X}^{2}=8.484(\mathrm{p}=0.014<0.05)$. The data are also showed in Table 5. The difference of gender accords with the psychological gender differences: males are rational and careless; females are sensitive and considerate. The difference between students from city and those from countryside can be traced back to the current social situation. Students from city are all live in good conditions, and with an optimistic world view, while students from countryside had leaded a hard life. After they came to the university, they realized that the academic performance is not the only measurement of being excellent. 
Table 4. The relation between family members and the object of thanksgiving.

\begin{tabular}{|c|c|c|c|}
\hline \multicolumn{4}{|c|}{ The person that to whom you feel the most grateful } \\
\hline \multicolumn{2}{|c|}{ Classification } & Parents & $\begin{array}{c}\text { Others } \\
\text { (individual, society or country) }\end{array}$ \\
\hline \multirow{3}{*}{ Family members } & The only child & $97.20 \%$ & $2.80 \%$ \\
\hline & With one sibling & $88.80 \%$ & $11.30 \%$ \\
\hline & With 2 or more siblings & $97.30 \%$ & $2.70 \%$ \\
\hline \multicolumn{2}{|c|}{ Total } & $100 \%$ & $100 \%$ \\
\hline \multicolumn{2}{|c|}{ Significance } & \multicolumn{2}{|c|}{$\mathrm{X}^{2}=6.753, \mathrm{df}=2, \mathrm{p}=0.037$} \\
\hline
\end{tabular}

Table 5. The relation between gender, homeplace and the gratitude to alma mater.

\begin{tabular}{|c|c|c|c|c|}
\hline \multicolumn{5}{|c|}{ Will you come back to visit your alma mater after your graduation? } \\
\hline & tion & $\begin{array}{c}\text { Yes, I am } \\
\text { concerned }\end{array}$ & $\begin{array}{l}\text { I will visit it if it } \\
\text { is by chance. }\end{array}$ & $\begin{array}{l}\text { No, nothing } \\
\text { interests me. }\end{array}$ \\
\hline \multirow{2}{*}{ Gender } & Male & $55.70 \%$ & $38.60 \%$ & $5.70 \%$ \\
\hline & Female & $72.10 \%$ & $27.90 \%$ & \\
\hline \multicolumn{2}{|c|}{ Significance } & \multicolumn{3}{|c|}{$\mathrm{X}^{2}=12.471 \mathrm{df}=2 \mathrm{p}=0.002$} \\
\hline \multirow{2}{*}{ Homepalce } & City & $81.70 \%$ & $18.30 \%$ & \\
\hline & Countryside & $61.60 \%$ & $36.00 \%$ & $2.40 \%$ \\
\hline \multicolumn{2}{|c|}{ Significance } & \multicolumn{3}{|c|}{$\mathrm{X}^{2}=8.484 \mathrm{df}=1 \mathrm{p}=0.014$} \\
\hline
\end{tabular}

So they become worried about their future and ascribe this kind of psychological gap to their senior high school, thus the negative emotions grow.

\subsection{The Factor of Grades}

Teachers' teaching methods count a lot, and different kinds of modes of instruction can directly determine the consequence of gratitude education. Students from different grades have different feelings toward teacher's teaching methods.

Example is better than precept. The results indicate that, surprisingly, 50\% students of different personality reached an agreement on the answer "not sure", when they were asked the question "Will you hate a teacher because of his bad teaching method of gratitude education?" The relation between grades and teaching methods is close. To the same question, $5.9 \%$ of the freshmen, $21.4 \%$ of the sophomore and $21.2 \%$ of the junior and senior students chose the answer "Yes, I'll not attend his class any more". And 31.4\%, 21.2\% and $46.2 \%$ of these students chose the answer "No, I think though he did not make this class attractive, he did a lot for the preparation". Plus, $\mathrm{p}=0.01<0.05$. Nearly no freshmen would skip classes, because they have just entered university, and are not sure about the gratitude classes. While they become familiar with college life, they become sophomores and are gradually not willing to attend this class. It is well to be reminded that junior and senior students still respect teachers' fruits of labour when they find the teaching method is not that good. Maybe it is because 
that students in this stage, and they are cherishing their school day, so they showed gratitude to the teachers.

\section{Some Suggestions}

Through this survey and its following analysis, we find that in order to be effective in college students' gratitude education, we should keep pace with the times and teach students in accordance with their characteristics.

1) Reinforce the gratitude education on the basis of Chinese traditional culture.

Being thankful is a moral virtue of our Chinese, and also a basic quality of a man. College students, as the elites in a society, should bear this in mind, and be grateful to his life. Gratitude, as an important part of university education, should be done seriously. The post-90s college students are the main part in today's campus, who are independent, and confident; and also there is a need to receive gratitude education. These all make gratitude education possible.

2) Pay high attention to the gratitude education of some disadvantaged students (such as those from countryside).

"Among the present students from countryside, the gratitude awareness and actions (to perform the filial duty) are weakened; and they become self-centered and indifferent." (Wang, 2010) With the development of modernization construction, rural migrant workers are becoming more, and most of them are young parents, leaving their children hometown. Those leftover children are lack of gratitude education. For a long time, gratitude education is weakened in the rural area, which even results in a "vacuum zone" in rural family education; that is, children are lack of gratitude awareness (Zhang, 2011). So it should become an important issue that how to care about them, how to bring them more happiness after they enter college.

3) The teacher is critical in the implementation of gratitude education.

A teacher is the one with profound knowledge, and model is the one with noble morality. A teacher "should have a decent personality, set himself an example, which is a basic quality of a teacher" (Zhang, 2005). He is the person in charge. His setting himself as an example and his teaching method can directly affect the teaching result. Nowadays, college students spare lots of time learning and living in the campus, so their connection with teachers is close. The most profound, appealing, effective educational method is still Practice What You Preach. Teachers' deeds may influence students' character unconsciously, yet their indecent deeds can also impress students. Thus, teachers' negative example is also a great reason of the lack of gratitude awareness.

4) Gratitude education should be enriched and be more social.

With the broadening view of students, they could realize that the object of gratitude can be not only a family member but also a social individual. The man that should be thanked can vary from parents, teachers to the nature and society. Those objects are the key to the construction of a harmonious society. By being 
grateful to the nature's selfless supply, college students can strengthen their environmental consciousness. By understanding the society's caring for them, students can establish a sense of being master, and devote themselves into the society's construction and development. They temper and steel themselves, and become confident to their future. The diversity and timeliness of the content makes gratitude education more humanized and helpful.

\section{References}

Niu, L. (2011). The Family Factors of the Weakened Traditional Filial Piety in Rural Areas. Journal of JiNing University, 5, 100-103.

Wang, P. (2010). Calling for Filial Conduct and Moral Virtues and Being Grateful to the Ancestors-From the Angle of College Students from Countryside. Journal of Inner Mongolia University for Nationalities, 6, 121-124.

Zhang, R. J. (2011). A Brief Talk about the Behaviors of the after 90's and the Countermeasures. Law and Social Development, 5, 234-235.

Zhang, X. F. (2005). A Brief Talk about Being a Teacher and a Man. Heilongjiang Education, 9, 43-45. 